\title{
A T-shaped partial ground microstrip patch antenna based UHF sensor for partial discharge detection
}

\author{
Nayli Adriana Azhar, Norazizah Mohd Aripin, Goh Chin Hock, \\ Nayla Ferdous, Saidatul Hamidah \\ College of Engineering, Universiti Tenaga Nasional (UNITEN), Malaysia
}

\begin{tabular}{|c|c|}
\hline Article Info & ABSTRACT \\
\hline Article history: & Continuous partial discharge (PD) monitoring and early PD detection is \\
\hline Received Feb 10, 2020 & important in making sure the necessary preventative measures can be taken \\
\hline Revised Apr 19, 2020 & antenna that is able to detect PD signal within the UHF range. The antenna \\
\hline Accepted May 4, 2020 & $\begin{array}{l}\text { was designed and simulated using CST Microwave Studio. The antenna was } \\
\text { then fabricated using FR4 substrate material and tested for reception test. }\end{array}$ \\
\hline Keywords: & $\begin{array}{l}\text { The simulation results and the analysis from the fabricated antenna } \\
\text { confirmed that the proposed antenna able to detect PD signal at UHF range }\end{array}$ \\
\hline Microstrip patch antenna & (specifically at about $500 \mathrm{MHz}$ ) and fulfilled the design requirements in \\
\hline Partial discharge & $\begin{array}{l}\text { terms of the return loss, VSWR, bandwidth and gain. Reception test had } \\
\text { confirmed that the proposed antenna was able to detect PD signals that are }\end{array}$ \\
\hline Return loss & located at maximum distance, ranges from $37 \mathrm{~cm}$ to $70 \mathrm{~cm}$ (depending on \\
\hline UHF & the PD signal strength). The proposed antenna also had succesfully detected \\
\hline VSWR & $\begin{array}{l}\text { PD occurances at } 300 \mathrm{MHz} \text { to } 700 \mathrm{MHz} \text {. In conclusion, the proposed } \\
\text { T-shaped partial ground microstrip patch antenna had been successfully }\end{array}$ \\
\hline
\end{tabular}

Copyright $\odot 2020$ Institute of Advanced Engineering and Science. All rights reserved.

\section{Corresponding Author:}

Norazizah Mohd Aripin,

College of Engineering,

Universiti Tenaga Nasional, Malaysia.

Email: norazizahm@uniten.edu.my

\section{INTRODUCTION}

Partial discharge (PD) occurrences in high voltage equipments is one of major concerns in power utility industry, as it may lead to inconvenient power outage and involves cost intensive repairs. PD is an electrical discharge that do not completely or partially bridge the insulation between conductors and which can or cannot occur adjacent to a conductor [1]. The physical symptom appears such as visible burn marks at the solid insulation. Particularly in high voltage cable, PD can be the result of improper installation or poor cable with weak spots such as void and cracks. Therefore, PD measurement is critical process during on-site cable commissioning. PD monitoring and early detection is also crucial in routine maintenance to prevent unexpected equipment failure.

There are several conventional PD detection methods that are popularly deployed in industries such as electrical detection, acoustic detection, optical detection, and dissolved gas presence method [2-5]. They are known as conventional methods. In [6], it was reported that PD signal also emits electromagnetic waves within $300 \mathrm{MHz}$ to $1.5 \mathrm{GHz}$, which falls within the ultra high frequency (UHF) range. Recently, there is a growing interest in investigating UHF based PD signal in gas insulated substation (GIS) transformer, power transformer and cable [7-9]. The UHF based PD detection is a promising alternative to the conventional PD detection methods due to its robustness to interference, high sensitivity, detection accuracy and detection localization. In substation, noise is usually prevalent at lower frequency range (less than 200 $\mathrm{MHz}$ ), which can be easily eliminated by the UHF based PD detection [9]. In [10], Judd et. al stated that 
interference from communication systems that coexist in the UHF range is not a serious concern because PD event is an impulse signal, which is possible to discriminate and extracted from the polluted signal. Additionally, the author mentioned that with appropriate positioning of the UHF sensors, locating the PD sources can be achieved by comparing the signals captured from different sensor positions. UHF based PD detection in high voltage equipment is very much dependent to the UHF sensor performances. In designing a good UHF sensor for PD detection, the following requirements need to be carefully addressed:

a) Operating frequency band

The frequency band of the UHF antenna should be within the PD signal, which ranges from $300 \mathrm{MHz}$ to $1500 \mathrm{MHz}$.

b) Radiation pattern

Various UHF antennas have been proposed in literature, namely monopole antenna [6, 11-13], fractal antenna [14, 15], Hilbert antenna [16, 17], Archimedean antenna [18] and microstrip patch antenna [19-21]. However, most of these antennas are directional antenna. Using directional antenna, the maximum gain is towards where the PD signal frequently occurs. However, the location of PD source is typically unknown. Hence, omnidirectional antenna pattern, which receives signal from all direction would be more advantageous and offer higher accuracy in detecting the PD signal.

c) Maximum distance of UHF antenna placement within the high voltage equipments.

This is to ensure that the antenna can be placed at location within its detection range from the PD source.

The designed antenna should also fulfill performance metrices in terms of return loss (S11), voltage standing wave ratio (VSWR), directivity and gain. This paper presents our proposed T-shaped partial ground microstrip patch antenna that can be used as UHF sensor for partial discharge detection. The proposed antenna is designed to resonant at $500 \mathrm{MHz}$, motivated by the simulation and experiment conducted on high voltage equipments in $[11,19]$. The standard microstrip patch antenna, which can be either square, rectangular or circular in shape, are usually exhibited directional radiation pattern [22-24]. Applying complex geometrical shape, the microstrip patch antenna could produce omnidirectional pattern [8,25] and affects the bandwidth [26]. In [27], our initial microstrip patch antenna was based on a rectangular full ground plane. The work is extended here with the T-shaped partial ground plane, to achieve omnidirectionality. Hence it could detect PD signal from any direction. The antenna's detection range is also studied here. In summary, the contribution of this paper is in twofolds; (i) design of T-shaped microstrip patch antenna that can detect unknown PD signal within UHF range (ii) PD signal detection range.

\section{RESEARCH METHOD}

There are several parameters that need to be carefully considered when designing a microstrip patch antenna, such as the substrate material, physical characteristics of the patch, the feeding technique and the geometrical shapes of the antenna. The proposed antenna is based on FR4 board, having dielectric constant, \&r of 4.3. There are 4 common feeding techniques, namely inset coupling, coaxial coupling, proximity coupling and aperture coupling. In this work, inset coupling technique is adopted, with the conducting strip connected directly at the edge of the microstrip patch. This creates a planar structure to the antenna and hence offer better impedance matching compared to other feeding techniques [28, 29]. Figure 1 illustrates the front view of the proposed T-shaped partial ground antenna, showing the inset coupling and a rectangular shape. In order to improve the gain and bandwidth, researchers have proposed several techniques such as slots, notching, parasitic element, partial ground and optimizing the antenna's geometrical shape [30-32]. In this work, the T-shaped partial ground technique as shown in Figure 2 is adopted to improve the bandwidth and gain.

The design parameters of the proposed antenna are tabulated in Table 1. The proposed antenna is designed and simulated using CST Microwave Studio software. The antenna is then fabricated using FR4 with double copper cladding and the performance is tested using vector network analyzer. Figure 3 and Figure 4 shows the fabricated antenna. The fabricated antenna is also validated for reception test, to observe its' ability in detecting the PD signal and to determine the maximum distance for antenna placement. Prior to the reception test, $\mathrm{m}-\mathrm{dB}$ method is used to determine the noise threshold. The $\mathrm{m}$ - $\mathrm{dB}$ method allows a margin of $\mathrm{m}-\mathrm{dB}$ above the measured average noise value. The $\mathrm{m}-\mathrm{dB}$ margin is set to clearly differentiate the PD signal from the noise. It is also to avoid unnecessary false alarm, which assumes noise as a PD signal. The $\mathrm{m}-\mathrm{dB}$ method has been widely used in detecting unused spectrum in wireless communication $[33,34]$. In this work $5 \mathrm{~dB}$ margin is chosen based on our measurement and observation of noise. The measured average noise is $-77 \mathrm{dBm}$ and thus the noise threshold is set to $-72 \mathrm{dBm}$. It would mean that any signal that is above $-72 \mathrm{dBm}$ is considered as PD signal. 
The reception test is carried out in the laboratory. Block diagram of the experimental setup for the reception test is illustrated in Figure 5. The PD source is generated by a signal generator (GWINSTEK USG-LF44), connected to the T-shaped partial ground antenna that acts as transmitter. Another similar T-shaped partial ground antenna that acts as receiver is connected to ADVANTEST U3571 spectrum analyzer. Parameters of PD source are configured using USG software, while the detected PD signals are monitored using spectrum analyzer and UV37000s software. Referring to [35], the PD signal can be as low as $-10 \mathrm{dBm}$ or $100 \mathrm{mV}$. In the reception test, the PD signal source is set from $-10 \mathrm{dBm}$ (min) to $0 \mathrm{dBm}(\max )$. The spectrum analyzer is set to monitor the received PD signal from $300 \mathrm{MHz}$ to $700 \mathrm{MHz}$, with centre frequency of 500MHz.

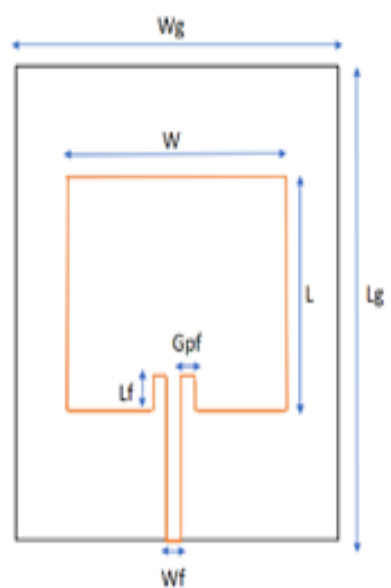

Figure 1. Front structure



Figure 2. T-shaped partial ground plane

Table 1. Design parameters of the T-shaped partial ground microstrip patch antenna

\begin{tabular}{lc}
\hline Parameters & Dimensions (mm) \\
\hline Antenna Width, W & 76 \\
Antenna Length, L & 140 \\
Substrate Width, Wg & 84 \\
Substrate Length, Lg & 226 \\
Feedline Length, Lf & 15 \\
Feedline Width, Wf & 3 \\
Feedline Gap, Gpf & 1 \\
Partial Ground Length, Lb & 192 \\
Partial Ground Width, Wb & 20 \\
Substrate Height, Hs & 1.6 \\
Copper Height, Ht & 0.035 \\
\hline
\end{tabular}

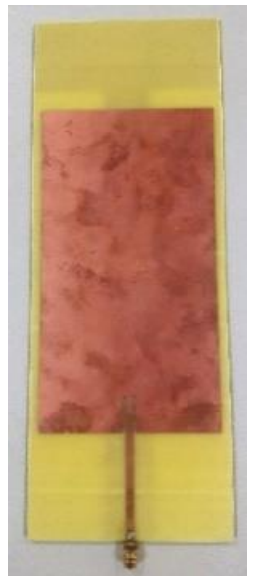

Figure 3. Front view of the fabricated antenna

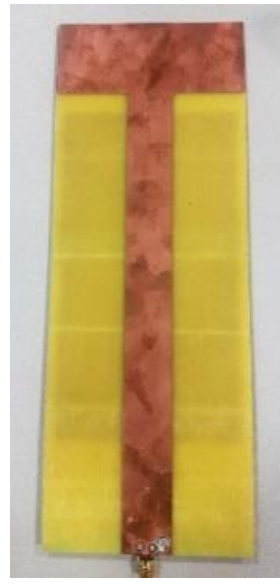

Figure 4. T-shaped partial ground 


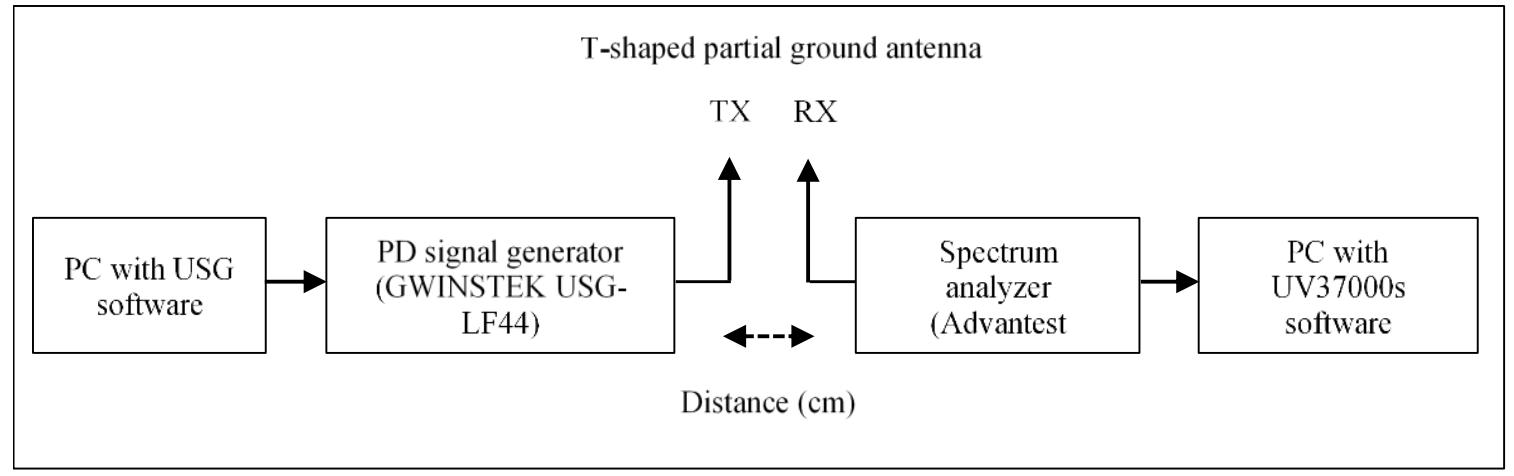

Figure 5. Setup for the reception test

The performances are evaluated in terms of return loss (S11), VSWR, directivity and gain. The requirement for $\mathrm{S} 11$ should be less than $-10 \mathrm{~dB}$, which means that only $10 \%$ of power signal is reflected back and the remaining $90 \%$ shall be received by the antenna [36]. The VSWR is defined as reflection coefficient which describes the power reflected from the antenna. The ideal case of VSWR is 1 (unity) which indicates perfect match and there is no reflected power from the antenna [37]. However, VSWR of less than 2 is expected in this work. Antenna directivity is used to evaluate the concentration of the antenna radiation pattern in a particular direction. An antenna that radiated equally well in all directions would be omnidirectional. The antenna gain is defined as radiation efficiency multiply with the directivity.

\section{RESULTS AND ANALYSIS}

This section presents the results from the CST simulation, measurements from fabricated antenna and also the reception test. Figure 6 depicts that the simulated antenna attained return loss of $-48 \mathrm{~dB}$, while the fabricated antenna obtained $-28.83 \mathrm{~dB}$. Although the $\mathrm{S} 11$ of the fabricated antenna is largely different than the simulation, it fulfills the $\mathrm{S} 11$ requirement of less than $-10 \mathrm{~dB}$. The graph also shows that the simulation result attained resonant frequency of $500 \mathrm{MHz}$ with bandwidth of $68 \mathrm{MHz}$ (474 MHz to $542 \mathrm{MHz}$ ). On the other hand, the fabricated antenna achieved resonant frequency of $504 \mathrm{MHz}$ with bandwidth of $58 \mathrm{MHz}$ (468 MHz to $526 \mathrm{MHz}$ ). Figure 7 depicts closer look of the VSWR performance at around $500 \mathrm{MHz}$. It is observed that the VSWR from simulation is 1.008 , while the fabricated antenna achieved slightly higher VSWR of 1.26. Both VSWR values achieved the target of less than 2. Simulation result also shows that the maximum gain is $1.951 \mathrm{~dB}$.



Figure 6. The S11 performance of the T-shaped partial ground antenna

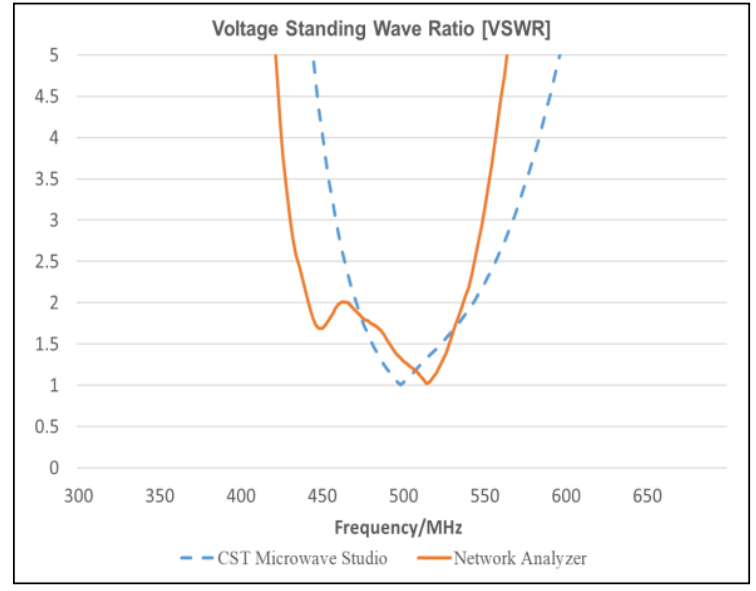

Figure 7. VSWR performance of the T-shaped partial ground antenna 
In contrast to the simulated antenna, the overall performance of the fabricated T-shaped partial ground microstrip patch antenna is slightly lower. It might be due several factors such as material oxidation from lengthy exposure, quality of the FR4 substrate and fabrication losses. Whereas the results from simulation are based on ideal conditions. Nevertheless, it can be concluded that the overall performance of the fabricated antenna is in a good agreement with the simulation results. The fabricated T-shaped partial ground microstrip patch antenna is further analyzed in terms of (i) its ability to detect the PD signal and (ii) to determine the maximum distance of the antenna placement from the PD source. In this reception test, the PD signal is observed closely from $450 \mathrm{MHz}$ to $550 \mathrm{MHz}$, consistent with the optimal bandwidth of the fabricated antenna. The PD source is varied from $0 \mathrm{dBm},-5 \mathrm{dBm}$ and $-10 \mathrm{dBm}$, while the noise threshold is set to $-70 \mathrm{dBm}$. The farthest distance of the antenna placement is then observed accordingly. Figure 8, 9 and 10 show the received PD signal over the distance (in $\mathrm{cm}$ ). Based on those experimental results, the maximum distance of the antenna placement is recorded in Table 2. As expected, the maximum distance became shorter as the PD signal became weaker. However, since the proposed antenna is omnidirectional, it is able to receive and detects PD signal from any direction which is unknown. This clearly shows that the proposed T-shaped partial ground microstrip antenna is functional well and able to detect the PD signal at up to certain distance.

Table 2. Maximum distance of the antenna placement

\begin{tabular}{cc}
\hline PD signal source $(\mathrm{dBm})$ & Maximum distance $(\mathrm{cm})$ \\
\hline 0 & 70 \\
-5 & 56 \\
-10 & 37 \\
\hline
\end{tabular}

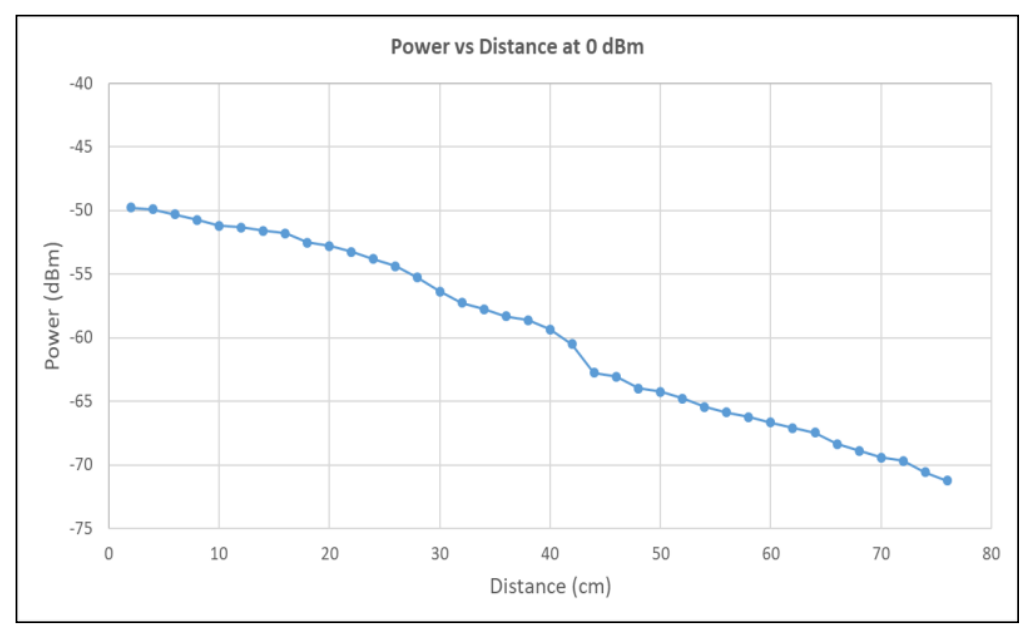

Figure 8 . The detected PD vs distance at $0 \mathrm{dBm}$



Figure 9. The detected PD vs distance at $-5 \mathrm{dBm}$ 


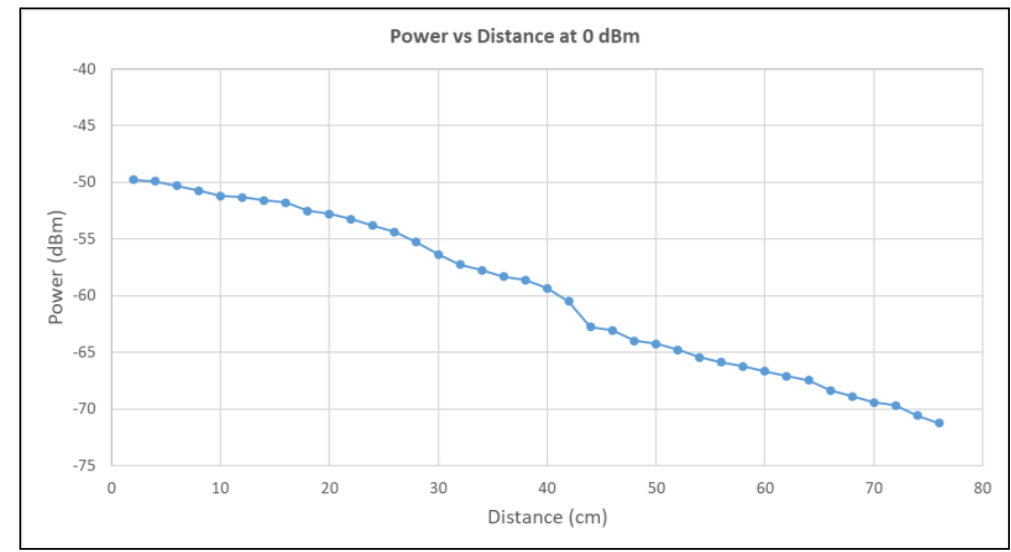

Figure 10. The detected PD vs distance at $-10 \mathrm{dBm}$

The observation window for the reception test is then further expanded from $300 \mathrm{MHz}$ to $700 \mathrm{MHz}$. The objective is to evaluate the trend of PD signal occurances within that frequency range. It is observed that the PD signals are consistently present at 312.4 MHz, 398.4 MHz, 595.6 MHz and 679.3 MHz. Table 3 presents the detected PD signal strength, for PD source of $0 \mathrm{dBm}$. The same trend is also witnessed for PD sources of $-5 \mathrm{dBm}$ and $-10 \mathrm{dBm}$. This test confirms that the proposed antenna is able to detect PD signal from 300 to $700 \mathrm{MHz}$.

Table 3. The detected PD at various frequencies (PD source of $0 \mathrm{dBm}$ )

\begin{tabular}{ccccc}
\hline $\begin{array}{c}\text { Distance } \\
\text { Frequency }(\mathrm{MHz})\end{array}$ & $5 \mathrm{~cm}$ & \multicolumn{4}{c}{$\begin{array}{c}10 \mathrm{~cm} \\
\text { Power }(\mathrm{dBm})\end{array}$} & $20 \mathrm{~cm}$ \\
\hline 312.4 & -57.84 & -64.02 & -64.27 & -65.82 \\
398.4 & -51.25 & -57.72 & -61.70 & -65.65 \\
595.6 & -50.69 & -54.40 & -56.33 & -59.96 \\
679.3 & -44.65 & -50.91 & -54.49 & -56.56
\end{tabular}

\section{CONCLUSION}

This paper presents our proposed T-shaped partial ground microstrip patch antenna that is designed specifically to detect PD signal that emits electromagnetic waves at UHF range. The proposed antenna is designed to resonant at $500 \mathrm{MHz}$. The design and simulation is carried out using CST Microwave Studio, fabricated on FR4 substrate, analyzed using vector analyzer and validated through reception test. Simulation results confirmed that the proposed antenna fulfills the performance requirements in terms of the return loss, VSWR, bandwidth and gain. Although the results for the fabricated antenna is slightly lower than the simulation results, but it is still within the acceptable range. Results from reception test also verified that the proposed antenna has successfully detecting the PD signal, up to certain maximum distance $(37 \mathrm{~cm}$ to $70 \mathrm{~cm})$. Additionally, the proposed antenna had also successfully detected PD occurances at $300 \mathrm{MHz}$ to $700 \mathrm{MHz}$. However, there are still a lot of improvements that can be done and is open for further investigations. For example, PD signal localization will help to improve the detection accuracy. In addition to that, the impact of structure of high voltage equipments to the electromagnetic waves need to be investigated further, especially on the actual high voltage.

\section{ACKNOWLEDGEMENTS}

A special thanks to the Innovation \& Research Management Center (iRMC), Universiti Tenaga Nasional for the research funding under the Uniten Internal Grant 2018 (UNIIG 2018).

\section{REFERENCES}

[1] F Radzi, N H Nik Ali, N Rameli, A Mohd Ariffin, M S Abd Rahman, M R Ahmad, and A S Salleh, "Partial discharge detection device using ultrasonic sensor on medium voltage XLPE cable," Indonesian Journal of Electrical Engineering and Computer Science, vol. 17, no. 2, pp. 886-894, 2020.

[2] I. A. Soomro and N. Ramdon, "Study on different techniques of partial discharge detection in power transformers winding: Simulation between paper and EPOXY resin using UHF method," Int. J. Conceptions Electr. Electron. Eng., vol. 2, pp. 57-61, 2014. 
[3] M. M. Yaacob, et al, "Review on partial discharge detection techniques related to high voltage power equipment using different sensors," Photonic Sensors, vol. 4, no. 4, pp. 325-337, 2014.

[4] A. Mukhtaruddin, et al, "Techniques on Partial Discharge Detection and Location Determination in Power Transformer," 3rd Int. Conf. Electronic Devices, pp. 537-542, 2016.

[5] Yoma O. Shaker, "Detection of partial discharge acoustic emission in power transformer," International Journal of Electrical and Computer Engineering (IJECE), vol. 9, no. 6, pp. 4573-4579, 2019.

[6] R. Rostaminia, M. Saniei, M. Vakilian, and S. S. Mortazavi, "Evaluation of transformer core contribution to partial discharge electromagnetic waves propagation," Int. J. Electr. Power Energy Syst., vol. 83, pp. 40-48, 2016.

[7] Y. Wang, J. Wu, W. Chen and Y. Wang, "Design of a UHF Antenna for partial discharge detection of power equipment," Journal of Sensors, Hindawi Publishing Corporation, vol. 2014, pp. 1-8, 2014.

[8] H. Chai, B. T. Phung, and S. Mitchell, "Application of UHF sensors in power system equipment for partial discharge detection: A review," Sensors, vol. 19, no. 5, 2019.

[9] Luiz A. M. M. Nobrega, George V. R. Xavier, Marcus V. D. Aquiono, Alendandre J. R Serres, Camila C. R. Albuquerque and Edson G. Costa, "Design and development of bio-inspired UHF sensor for partial discharge detection on power transformers," Sensors, vol 19, no. 3, 2019.

[10] Judd, M.D.; Li, Y.; Hunter, I.B.B., "Partial discharge monitoring for power transformers using UHF sensors, part 1: Sensors and signal interpretation," IEEE Electrical Insulation Magazine, vol. 21, no. 2, pp. 5-14, 2005.

[11] $\mathrm{M}$. Wu, et al, "An overview of state-of-the-art partial discharge analysis techniques for condition monitoring," IEEE Electr. Insul. Mag., vol. 31, no. 6, pp. 22-35, 2015.

[12] J. Do Nascimento Cruz, et al., "Bio-inspired printed monopole antenna applied to partial discharge detection," Sensors, vol. 19, no. 3, 2019.

[13] J. Do Nascimento Cruz, et al, "UWB printed monopole antennas for application in detection of partial discharges," 12th European Conference on Antennas and Propagation (EuCAP 2018), pp. 1-5, 2018

[14] C. Yao, P. Chen, C. Huang, Y. Chen, and P. Qiao, "Study on the application of an ultra-high-frequency fractal antenna to partial discharge detection in switchgears," Sensors, vol. 13, no. 12, pp. 17362-17378, 2013.

[15] F. Wang, F. Bin, Q. Sun, J. Fan, F. Liang, and X. Xiao, "A novel UHF M inkowski fractal antenna for partial discharge detection," Microw. Opt. Technol. Lett., vol. 59, no. 8, pp. 1812-1819, 2017.

[16] J. Li, T. Jiang, C. Wang, and C. Cheng, "Optimization of UHF Hilbert antenna for partial discharge detection of transformers," IEEE Trans. Antennas Propag., vol. 60, no. 5, pp. 2536-2540, 2012.

[17] P. Wang, F. Kuang, M. Liu, and Q. Zhou, "UHF enclosed Hilbert antenna for partial discharge on-site testing", 2016 IEEE International Conference on High Voltage Engineering and Application (ICHVE), pp. 1-4, 2016.

[18] Y. Zhang and I. Glover, "Design of an ultrawideband VHF/UHF antenna for partial discharge detection," 2014 IEEE Int. Conf. Signal Processing, Communication \& Computer, pp. 487-490, 2014.

[19] B. Sarkar, et al, "Microstrip patch antenna based UHF sensor for detection of partial discharge in high voltage electrical equipments," 11th IEEE India Conf. Emerg. Trends Innov. Technol., pp. 1-6, 2014.

[20] F. Yang, C. Peng, Q. Yang, H. Luo, I. Ullah, and Y. Yang, "An UWB printed antenna for partial discharge UHF detection in high voltage switchgears," Prog. Electromagn. Res. C, vol. 69, pp. 105-114, 2016.

[21] G. V. R. Xavier, et al, "Design and application of an UHF microstrip circular antenna for partial discharges detection in power transformers," IEEE Int. Conf. High Volt. Eng. Appl., pp. 2-5, 2018.

[22] S. K. Sidhu and J. Singh Sivia, "Comparison of different types of microstrip patch antennas," Int. J. Comput. Appl., vol. 975, pp. 12-16, 2015.

[23] A. A. Bhoot, S. A. Memon, A. Ahmed, and S. Hussain, "Comparative study of microstrip patch antenna with different shapes and its application,” 2019 2nd Int. Conf. Comput. Math. Eng. Technol., pp. 1-8, 2019.

[24] H. Yon, et al, "Developed high gain microstrip antenna like microphone structure for 5G application", International Journal of Electrical and Computer Engineering (IJECE), vol. 10, no. 3, pp. 3086-3094, 2020.

[25] J. Dong, "Novel design of omnidirectional microstrip patch antenna," Proc. Wirel. Opt. Commun. Conf., pp. $1-3,2013$.

[26] S. S. Gültekin, D. Uzer, R. Top, E. Uğurlu, and Ö. Dündar, "A comparison of different patch geometry effects on bandwidth," International Journal of Applied Mathematics, Electronics and Computers, vol. 4, pp. 421-423, 2016.

[27] N. A. Azhar and N. M. Aripin, "Feasibility study of partial discharge detection of electrical assets based on electromagnetic field emissions," International Graduate Conference on Energy, Engineering, Technology \& Business Management, 2019.

[28] S. Bisht, S. Saini, et al, "Study the various feeding techniques of microstrip antenna using design and simulation using CST microwave studio,” Int. J. Emerg. Technol. Adv. Eng., vol. 4, no. 9, pp. 318-324, 2014.

[29] A. Arora, et al, "Comparative study of different feeding techniques for rectangular microstrip patch antenna," Int. J. Innov. Res. Electr. Electron. Instrum. Control Eng., vol. 3, no. 5, pp. 32-35, 2015.

[30] T. Agale and M. M. Khanapurkar, "A review on design approach for performance enhancement techniques of microstrip patch antenna," 2017 Third International Conference on Advances in Electrical, Electronics, Information, Communication and Bio-Informatics (AEEICB), pp. 436-440, 2017.

[31] A. H. Abdelgwad, "Microstrip patch antenna enhancement techniques," Intenational J. Electron. Commun. Eng., vol. 11 , no. 10, pp. 703-710, 2018.

[32] Abhishek Viswanathan and Rajasi Desai, "Applying partial ground technique to enhance bandwidth of UWB circular microstrip patch antenna," International Journal of Scientific \& Engineering Research, vol 5, issue 10, pp. 780-784, 2014. 
[33] T. Harrold, R. Cepeda, and M. Beach, "Long-term measurements of spectrum occupancy characteristics," 2011 IEEE Int. Symp. Dyn. Spectr. Access Networks, pp. 83-89, 2011.

[34] M. H. Islam, et al., "Spectrum survey in Singapore: Occupancy measurements and analyses," 2008 3rd International Conference on Cognitive Radio Oriented Wireless Networks and Communications (CrownCom 2008), pp. 1-7, 2008.

[35] B. Sarkar, C. Koley, N. K. Roy, and P. Kumbhakar, "Low cost RF sensor for partial discharge detection of high voltage apparatus," 2013 IEEE 1st International Conference on Condition Assessment Techniques in Electrical Systems (CATCON), pp. 259-264, 2013.

[36] U. Kashyap, Sreenath, and Raithatha, "Microstrip patch antenna for ISM band applications," Int. J. Emerg. Technol. Adv. Eng., vol. 5, no. 5, pp. 233-234, 2015.

[37] P. Kumar, A. Kumar, and S. Panda, "Design of a unique microstrip patch antenna with optimum gain," 2015 Int. Conf. Commun. Signal Process. ICCSP 2015, pp. 403-405, 2015.

\section{BIOGRAPHIES OF AUTHORS}
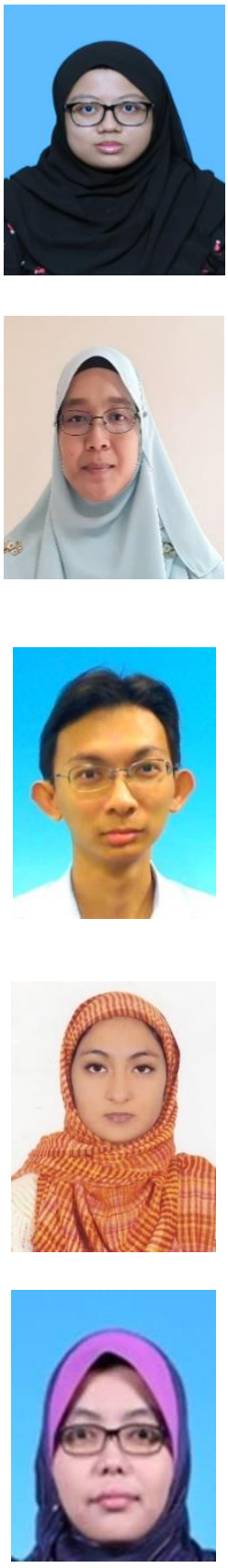

Nayli Adriana Azhar received her B.Eng. degree in Electrical and Electronics Engineering from Universiti Tenaga Nasional (UNITEN), Malaysia in 2019. She is currently pursuing her M.S degree in Electrical Engineering at UNITEN. She is also a Research Assistant with a project under UNITEN iRMC. Her research interest includes antenna design and telecommunications.

Norazizah Mohd. Aripin obtained her $\mathrm{PhD}$ in Electrical Engineering from Universiti Teknologi Malaysia in 2013. She received her Bachelor degree and Master's degree in communication and computer engineering from the Universiti Kebangsaan Malaysia in 2001 and 2005, respectively. Currently, she is a Senior Lecturer with the Department of Electrical \& Electronics Engineering, Universiti Tenaga Nasional (UNITEN) Malaysia. She is a Corporate Member of Institute of Engineers Malaysia (IEM) and Board of Engineers Malaysia (BEM). Her current research interest includes antenna design, 5G wireless communication, multimedia transmission over cognitive UWB, cross-layer optimization in wireless networks, and cognitive radio technology.

Goh Chin Hock received his Bachelor Degree in Electrical and Electronics Engineering in 2004 as well as Master and PhD in Electrcal Engineering in 2008 and 2012 respectively from Universiti Tenaga Nasional, Malaysia. He is currently a Senior Lecturer with the Department of Electrical and Electronics Engineering, Universiti Tenaga Nasional. He is the Professional Engineer of Board of Engineers Malaysia (BEM), Energy Professional of MEPA and Corporate Member of Institute of Engineers Malaysia (IEM). Besides that, he is Certified Energy Manager (CEM) and Certified Professional in Measurement and Verification (CPMV). His work and research interest includes, advanced material and energy, electromagnetic technology and smart cities solution.

Nayla Ferdous is currently doing her Master Degree in Electrical Engineering at Universiti Tenaga Nasional, Kajang, Malaysia. She obtained her Bachelor of Electrical \& Electronics Engineering with academic distinction of Magna Cum Laude from American International University Bangladesh, Dhaka, Bangladesh. Her research interest includes antenna and propagation, wireless communication and wireless energy harvesting.

Saidatul Hamidah Bt Abd Hamid received B.Sc. (Hons) in Electric and Electronic Engineering from Universiti Tenaga Nasional in 2010. She worked in manufacturing field as a Software and Test Engineer from 2011 until 2015. She obtained her M.Sc in Telecommunication and Information Engineering from UiTM, Shah Alam in 2018. Presently, she is doing Ph.D study in Electrical Engineering at Universiti Tenaga Nasional, Malaysia. She also presently with UNITEN Research and Development Sdn. Bhd. as a Research Engineer. Her research interest includes antenna design and propagation, reconfigurable antennas and miniaturization, metamaterials and wireless energy harvesting. 